\title{
Predictability and number of pairings in the establishment of a secondary reinforcer ${ }^{1}$
}

\author{
BARRY L. JACOBS ${ }^{2}$ \\ UNIVERSITY OF CALIFORNIA, LOS ANGELES
}

Rats were given appetitive secondary reinforcement training under three conditions in a Skinner box. In the first condition, CSS and USs occurred randomly and independently; in the second condition, USS intermittently followed CSs, but did so within a specific time period; in the third condition, USs consistently followed CSs within a specific time period. Following acquisition, a test phase was given in which CSs were contingent upon bar pressing. The first condition resulted in less secondary reinforcement acquisition than either of the other two conditions.

Rescorla (1966) reported that CSs that predicted the time of occurrence of intermittent shock USs were more powerful elicitors of fear than CSs with identical US pairings that had additional USs randomly interspersed. This finding does not support the traditional view that in Pavlovian conditioning the temporal contiguity of CS and US are necessary and sufficient for establishment of a CR. Instead, it supports the position that the strength of conditioning is a function of the amount of information or predictability the CS conveys about the occurrence of the US. The number of CS-US pairings may be irrelevant to the establishment of a CR if the CS does not increase the predictability of the occurrence of the US. Two experiments by Egger \& Miller $(1962,1963)$ provided strong support for this view in an appetitive situation. The results of similar experiments in aversive situations by Seligman (1966) and Ayres (1966) almost equally strongly disconfirm this position and instead support the traditional Pavlovian conception of conditioning.

The present study was basically an attempt to replicate Rescorla's (1966) results in an appetitive rather than an aversive situation. One of Rescorla's three conditions was replaced by a continuous reinforcement condition in the present study. This controlled for the possibility that a difference in secondary reinforcement strength between the two other conditions (predictable but intermittent reinforcement and random reinforcement) was due to the partial reinforcement effect (PRE). The Ss in the predictable reinforcement condition received only $1 / 5$ as many USs as Ss in the random reinforcement condition. If the difference between these two conditions was due to a PRE, the intermittent reinforcement condition should also produce stronger secondary reinforcement than the continuous reinforcement condition.

A shorter VI than that used by Rescorla was used in the present experiment in order to maximize the probability of demonstrating the effect.

\section{Method}

The Ss were 18 naive male rats of the SpragueDawley strain between 85 and 115 days old at the beginning of the experiment. The Ss were placed on a deprivation schedule of $11 \mathrm{~g}$ of Purina lab chow per day at least two weeks before the first training session. Water was available ad lib.

The equipment consisted of a Skinner box housed in an ice chest equipped with an exhaust fan. CS and US presentations were programmed by two separate tape readers. The box was illuminated by a $15 \mathrm{~W}$ incandescent light. The CS was a 2 sec blackout; the US was a $45 \mathrm{mg}$ food pellet.

The experiment was conducted in six sessions of two days each. Three Ss, one from each condition, were run in each two day session. Each $\mathrm{S}$ was given $2 \mathrm{~h}$ of $\mathrm{sec}-$ ondary reinforcement training on the first day, $1 \mathrm{~h}$ of such training on the second day, followed $2 \mathrm{~h}$ later by a $1 \mathrm{~h}$ test for secondary reinforcement strength. The order in which the Ss were run remained the same for the three phases. All six possible orders of running three Ss were used.

On the first day, $\mathrm{Ss}$ in Condition $\mathrm{C}$ (control) received $12045 \mathrm{mg}$ food pellets on a VI $1 \mathrm{~min}$ schedule; 120 2 sec blackouts were independently programmed on a VI 1 min to occur randomly during the session. The six Ss in Condition $E$ (experimental) received a treatment identical to that of Condition $C$ except that they received only those USs programmed to occur within $12 \mathrm{sec}$ of the blackout onset. These Ss received an average of only 24 USs. The six Ss in Condition CRF (continuous reinforcement) received the same treatment as Condition $\mathrm{E}$ except that if a food pellet had not been received by the end of a $12 \mathrm{sec}$ period following blackout onset, a pellet was automatically presented.

The following day all Ss received the same treatment they received on the previous day, but the sessions were only one-half the duration (60 CSs and 60 USs were programmed). Immediately following the third S's training session, a bar was inserted into the Skinner box and a $1 \mathrm{~h}$ secondary reinforcement testing period was begun for the first $S$. This was immediately followed by $1 \mathrm{~h}$ test sessions for the second and third Ss. Each bar press produced the $2 \mathrm{sec}$ CS.

All Ss were given $1045 \mathrm{mg}$ food pellets in the home cage $10 \mathrm{~min}$ before the beginning of each day's training session; also, two pellets were placed in the food cup of the Skinner box before $\mathrm{S}$ entered. The Ss in Condition $\mathrm{E}$ were prefed with $4.5 \mathrm{~g}$ of lab chow 30 min prior to their 
Table 1. Number of bar presses during $1 \mathrm{~h}$ secondary reinforcement test session

\begin{tabular}{lrrrrrrr} 
& \multicolumn{9}{c}{ Group } & \multicolumn{1}{c}{} \\
Condition & 1 & 2 & 3 & 4 & 5 & 6 & Mean \\
\hline C & 65 & 24 & 91 & 77 & 23 & 58 & 56.3 \\
E & 100 & 50 & 141 & 112 & 92 & 72 & 94.5 \\
CRF & 100 & 60 & 148 & 129 & 41 & 141 & 103.2 \\
\hline
\end{tabular}

first training session and $2.25 \mathrm{~g}, 30 \mathrm{~min}$ prior to the second training session. This was done to equate hunger drive for all Ss at the end of each training session. All Ss were given the remainder of the day's $11 \mathrm{~g}$ ration 15 min after the third S's trials.

Results

Table 1 presents the mean number of bar presses for each condition and the total number of bar presses by each $\mathrm{S}$ in the test period. The variance between groups can be seen to be quite large, but in each group the number of responses by the $S$ in Condition $C$ was less than the number for the $S s$ in Conditions $E$ and CRF.

A conditions by groups analysis of variance showed both factors to be significant (conditions $-F=9.53$, df $=2 / 10, \mathrm{p}<.01$; groups $-\mathrm{F}=8.33, \mathrm{df}=5 / 10, \mathrm{p}<.01$ ). The latter difference, the variance due to the day on which the Ss were run, probably reflects uncontrolled variations in light, temperature, etc. A Newman-Keuls test (Winer, 1962) was then used to determine which specific conditions were significantly different. Condition $\mathrm{E}$ was significantly greater than Condition $C(p<.01)$; Condition CRF was also significantly greater than Condition $C(p<.01)$; there was no significant difference between Conditions $E$ and CRF ( $p>.05$ ).

Figure 1 presents the mean number of responses per condition in $5 \mathrm{~min}$ blocks. This figure demonstrates that the difference in conditions is due to a more rapid decline in response rate over time for Condition $\mathrm{C}$. This difference may be due to a more rapid extinction if the CS was established as a secondary reinforcer for Condition $\mathrm{C}$. If there was no secondary reinforcement acqui-

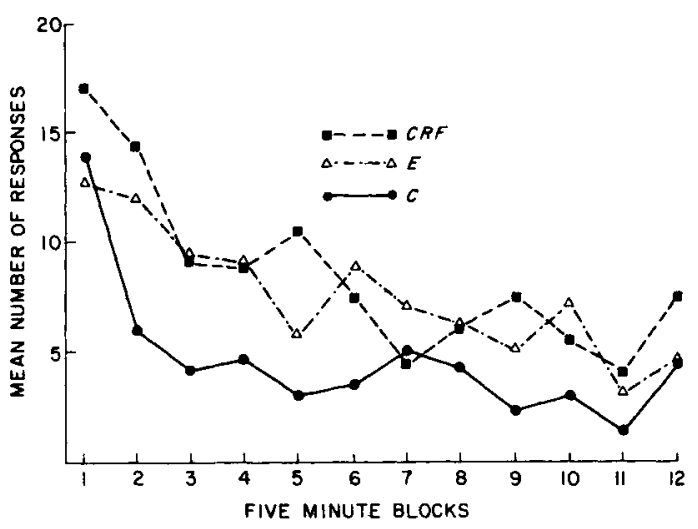

Fig. 1. Mean number of bar presses during testing for the three conditions, in 5 min blocks. sition for Condition $\mathrm{C}$, the difference may be attributable to habituation to the CS as a novel stimulus with response rates in Conditions $E$ and CRF being maintained by secondary reinforcement.

\section{Discussion}

The results of this experiment confirm and extend the findings of Rescorla (1966). The degree to which a CS allows $S$ to predict US presentations is an important variable in establishing a stimulus as a secondary reinforcer. This effect seems to be independent of the more traditionally emphasized number of CS-US pairings. The Ss in Condition $C$ received the same number of contiguous (within $12 \mathrm{sec}$ ) CS-US pairings as Ss in Condition $\mathrm{E}$, and additional pairings with greater CSUS intervals, yet the CS was less of a secondary relnforcer for this condition. Neither the present study nor Rescorla's distinguishes between two possible explanations for the effect. First, the inclusion of more USs for Condition $\mathrm{C}$ may have an inhibitory effect upon the leaming of the CS-US contingency. Second, it is possible that no differential secondary reinforcement is established because the CS is no better a predictor of the US than is the absence of the CS. Therefore, in the test situation, turning on one secondary reinforcer turns off the other, with a net effect of zero secondary reinforcement.

The finding that Condition $\mathrm{E}$ was not significantly greater than Condition CRF demonstrates that the present result was not due to a PRE and confirms the results of an experiment by Fox \& King (1961). They found that partial presentation of a US as compared to continuous presentation in acquisition did not establish a CS as a stronger secondary reinforcer when the CS was continually presented in the test phase. Thus, there is no evidence for the PRE with the usual secondary reinforcement paradigm in a bar pressing situation.

\section{References}

AYRES, J. J. B. Conditioned suppression and the information hypothesis. J. comp. physiol. Psychol, 1966, 62, 21-25.

EGGER, M. D., \& MILLER, N. E. Secondary reinforcement in rats as a function of information value and reliability of the stimulus. $J$. exp. Psychol, 1962, 64, 97-104.

EGGER, M. D., \& MILLER, N. E. When is a reward reinforcing? An experimental study of the information hypothesis. J. comp. physiol. Psychol., 1963, 56, 132-137.

FOX, R. E., \& KING, R. A. The effects of reinforcement scheduling on the strength of a secondary reinforcer. J. comp. physiol Psychol., 1961, 54, 266-269.

RESCORLA, R. R. Predictability and number of pairings in Pavlovian fear conditioning. Psychon. Sci., 1966, 4, 383-384.

SELIGMAN, M. E. P. CS redundancy and secondary reinforcement. $J$. exp. Psychol., 1966, 72, 546-550.

WINER, B. J. Statistical principles in experimental design. New York: MoGraw-Hill, 1962.

Notes

1. This research was supported by USPHS Grant MH-14173 to Dr. Eric Holman. The author wishes to thank Dr. Holman for his help, advice, and critical reading of this paper.

2. NSF graduate trainee. 